\title{
Diagnostic and Prognostic Benefits of Intra-Operative Enteroscopy in the Intestinal Epithelioid Angiosarcoma: case report
}

\author{
Alfadl Abdulfatah ${ }^{1}$ \\ ${ }^{1}$ University of Reims Central University Hospital
}

November 16, 2020

\begin{abstract}
Intestinal epithelioid angiosarcoma is an uncommon, aggressive and invasive neoplasm of vascular origin. We report a case of a 77-year-old male patient who was hospitalized with severe symptomatic anaemia due to bleeding jejunal ulcers and confirmed epithelioid angiosarcoma. Intraoperative enteroscopy enabled detection of multifocal bleeding lesions of the jejunum.
\end{abstract}

\section{Hosted file}

Angiosarcoma CR.pdf available at https://authorea.com/users/375976/articles/493146diagnostic-and-prognostic-benefits-of-intra-operative-enteroscopy-in-the-intestinalepithelioid-angiosarcoma-case-report 